\title{
Prevention of hepatitis B virus recurrence
}

\author{
James Fung ${ }^{1,2,3}$ \\ 'Department of Medicine, The University of Hong Kong, Hong Kong, China. \\ ${ }^{2}$ The Liver Transplant Center, Queen Mary Hospital, Hong Kong, China. \\ ${ }^{3}$ State Key Laboratory of Liver Research, The University of Hong Kong, Hong Kong, China.
}

Correspondence to: Dr. James Fung, Department of Medicine, Queen Mary Hospital, 102 Pokfulam Road, Hong Kong, China. E-mail: jfung@gastro.hk

How to cite this article: Fung J. Prevention of hepatitis B virus recurrence. Hepatoma Res 2021;7:33.

https://dx.doi.org/10.20517/2394-5079.2020.153

Received: 1 Dec 2020 First Decision: 25 Jan 2021 Revised: 1 Feb 2021 Accepted: 29 Mar 2021 Available online: 8 May 2021

Academic Editors: Geoff McCaughan, Ping An Copy Editor: Xi-Jun Chen Production Editor: Xi-Jun Chen

\begin{abstract}
Despite universal vaccination and antiviral therapies being available for decades, chronic hepatitis $B(\mathrm{CHB})$ remains the leading primary liver disease for liver transplantation in many parts of the Asia-Pacific region. The main indications include decompensated cirrhosis, severe acute flares, and hepatocellular carcinoma. Liver transplantation is not a sterilizing cure for $\mathrm{CHB}$ infection, therefore long-term antiviral prophylaxis is required. As the virus is never completely eradicated after transplant, the main goal of antiviral prophylaxis is to prevent reactivation, rather than recurrence or reinfection. Current available antiviral prophylaxis using nucleos(t)ide analogs (NUCs) \pm hepatitis B immunoglobulin (HBIG) are highly effective in preventing HBV reactivation after liver transplantation. Only NUCs with high potency and high barriers to resistance should be used, as there is still a risk of developing resistance and subsequent virological rebound and reactivation for older NUCs. Over the past decade, there has been a trend towards using less HBIG, with HBIG-free regimens showing excellent long-term outcomes and survival. Although cessation of prophylaxis may be feasible in a highly selected group, this should only be attempted within clinical trial settings, and life-long prophylaxis is still recommended. Future novel agents may restore the immune control of HBV, whereby antiviral therapy can be safely discontinued.
\end{abstract}

Keywords: Hepatitis B, hepatocellular carcinoma, recurrence, prophylaxis, antiviral

\section{INTRODUCTION}

Despite universal vaccination being available for over three decades, an estimated 248 million persons are 
chronically infected with the hepatitis B virus (HBV) globally, constituting a major health burden ${ }^{[1]}$. Longterm complications, including decompensated cirrhosis and hepatocellular carcinoma (HCC), together with severe acute flares, are the leading indicators for liver transplantation (LT) for patients with chronic hepatitis B (CHB) infection ${ }^{[2]}$. Since 1998, oral nucleos(t)ide analogs (NUCs) have become available, with the most recently approved agents being highly effective in suppressing HBV with minimal risk of resistance. In theory, long-term treatment should prevent the development of cirrhosis, decompensation, and acute flares, as well as lower the risk of $\mathrm{HCC}^{[3,4]}$. However, $\mathrm{CHB}$ remains the leading primary liver disease for LT in regions where infection remains at an endemic level ${ }^{[5]}$. The foremost reason for this is due to the fact that a significant proportion of persons infected remain undetected in the absence of a robust screening program and lack of access to NUCs; hence, only a minority of those who would benefit from antiviral therapy are being treated.

\section{LIVER TRANSPLANTATION FOR CHRONIC HEPATITIS B}

Although LT is curative for decompensated cirrhosis, HCC, and liver failure, it does not eradicate HBV from a chronically infected host (although it does remove the overwhelming pool of HBV) ${ }^{[6]}$. It is well documented that HBV can reside in extra-hepatic sites and remain as a source of reactivation after $\mathrm{LT}^{[7]}$. Even though the hepatocytes are the primary site of HBV DNA replication, viral replication outside has been demonstrated in pancreatic islet cells and renal proximal tubular epithelium ${ }^{[8,9]}$. Furthermore, covalently closed circular DNA (cccDNA), the stable template for HBV replication, can be found in extrahepatic tissues. Viral particles have also been demonstrated inside peripheral blood mononuclear cells, with the presence of cccDNA and active viral protein produced within lymphocytes ${ }^{[10-13]}$. Therefore, strictly speaking, for a chronically infected patient after LT, the role of prophylaxis is to prevent reactivation, rather than re-infection or recurrence of HBV. The reason is because the recipient has never achieved complete or sterilizing cure with LT, and hence the need for life-long antiviral prophylaxis.

\section{Definition of HBV recurrence and its limitations}

The status of HBV infection after LT is determined within the constraints of the current available biomarkers, namely qualitative hepatitis B surface antigen (HBsAg) and quantitative HBV DNA. In the absence of antiviral prophylaxis, uncontrolled viral replication is universal after LT, as evidenced by positive HBsAg in combination with a high viral load, leading to graft hepatitis and graft $\operatorname{loss}^{[14]}$. That is why, prior to the availability of effective antiviral prophylaxis, LT was contraindicated for those with active HBV infection.

Given that HBV is technically never completely eradicated, it is therefore not surprising that there is no standard definition of "recurrence" for HBV after LT. Most studies on determining the efficacy of antiviral regimens, including systemic reviews and meta-analyses, have focused on HBsAg status after LT to determine whether recurrence has occurred ${ }^{[15-17]}$. Although HBsAg is used routinely as a screening test for infection, a negative HBsAg in a chronically infected person does not equate to complete viral clearance, with underlying occult HBV infection ${ }^{[18]}$. Similarly, HBsAg negativity after LT does not signify eradication of the virus, as shown in Figure 1. Therefore, persistence of HBsAg after LT is not recurrence of infection to the effect that the HBV had never been eradicated in the first instance. Hence, there are limitations to defining "recurrence" when relying on imperfect virological markers, whereby a binary outcome of an insensitive qualitative HBsAg test determines the recurrence status.

\section{HBsAg positivity after liver transplantation}

Historically, HBsAg would have been an important marker of reactivation, especially prior to the advent of oral nucleos(t)ide analogs (NUCs). In the era where only hepatitis B immunoglobulin (HBIG) was available, 


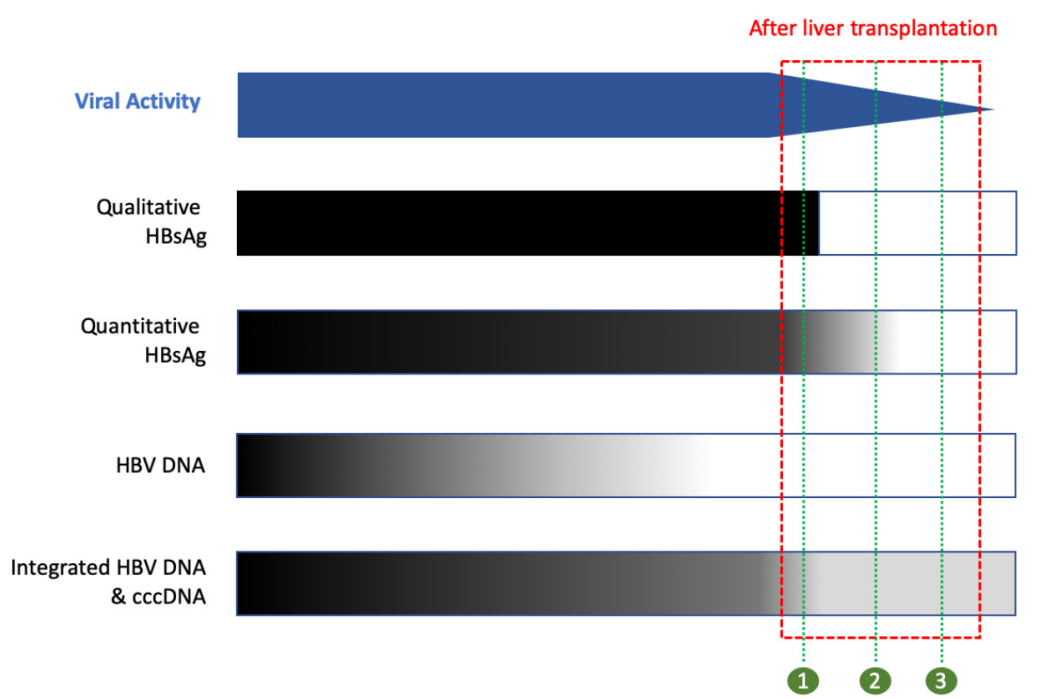

Figure 1. Schematic diagram of viral activity and viral biomarkers. The red box presents the period after liver transplantation. The blue bar presents the viral activity, with continual decline after liver transplantation. Black represents positive, white represents negative, and gray represents a gradient from high to low (dark to light). The green numbers represent a cross-section of the biomarkers after transplant: (1) HBsAg positive + HBV DNA negative; (2) HBsAg negative (but detectable with highly sensitive quantitative assays) + HBV DNA negative; and (3) HBsAg negative + HBV DNA negative (but with persistent integrated HBV DNA and cccDNA).

a positive HBsAg would have indicated failure of HBIG with associated virological rebound and subsequent poor graft outcome. However, with NUC treatment, the significant of HBsAg positivity has declined, except for the initial early periods with lamivudine, whereby a positive HBsAg may indicate underlying resistance and subsequent virological rebound. The risk of developing resistance with the current NUCs is minimal, and a positive HBsAg after LT is rarely associated with virological rebound ${ }^{[1,200}$.

With the use of NUCs with high barriers to resistance, a positive HBsAg status after LT can occur in the following scenario. Firstly, the HBsAg may remain persistently positive without any evidence of seroclearance. Secondly, HBsAg may reappear after initial HBsAg seroclearance. This may occur with passive transfer of donor antibodies which may render the HBsAg undetectable in the early post-transplant period until the antibody level gradually declines over time ${ }^{[21]}$. Occasionally, the HBsAg may fluctuate between negativity and positivity. Quantitative measurements of patients with positive HBsAg after LT have shown that the levels remain at extremely low levels, often at just above the threshold of detection for conventional qualitative tests ${ }^{[19]}$. This would indicate that the HBsAg status after LT is likely a continuum ranging from extremely low levels of HBsAg which may be undetectable using conventional qualitative assays to detectable levels albeit at low levels in the absence of true virological rebound [Figure 1]. Moreover, histological studies of HBsAg positive patients without virological rebound have shown no evidence of HBV-related pathology ${ }^{[22]}$. Therefore, rather than using the term "recurrence" when defining efficacy of prophylaxis in the current era of highly potent antiviral therapies, it would be more useful to determine efficacy of prophylaxis with clinically meaningful outcomes, including reactivation of HBV with virological relapse, whereby graft survival and survival will be impacted.

\section{HBsAg and HCC recurrence after liver transplantation}

The recurrence rate for early-stage HCC after LT is approximately $10 \%-20 \%{ }^{[23]}$. For patients transplanted for $\mathrm{HBV}$-related HCC, post-transplant positive HBsAg status is important because it raises the possibility of HCC recurrence ${ }^{[24]}$. There is a good correlation between the timing of HCC recurrence and HBsAg reappearance, and extra-hepatic tumor histology has been demonstrated to stain positive for $\mathrm{HBsAg}^{[25,26]}$. 
Removal of the tumor also leads to subsequent disappearance of detectable HBsAg in the serum. HBV antigens expressed in HCC may also potentially be targeted by immune therapeutic strategies ${ }^{[27]}$. These lines of evidence suggest that there is an association between HCC recurrence and HBsAg. The temporal correlation indicates that HBsAg reappearance may result from undetected extrahepatic tumor cells that carry low amount of pre-existing HBV, and, with tumor growth, viral amount gradually increases to a detection level. This may explain the significant association between HBV recurrence and HCC recurrence, with one study showing a 3.6 times higher likelihood of HCC recurrence in patients with HBV reinfection $^{[28]}$.

Recurrence of HCC is associated with poor survival and limited therapeutic options, with a median survival of less than 2 years $^{[29]}$, and classifying these patients as "recurrence" or "re-infection" of HBV because of HBsAg positivity can be misleading when determining antiviral efficacy. In fact, both the HCC recurrence and survival rates following LT for HCC for patients with CHB are comparable to those with HCCs associated with other primary liver diseases ${ }^{[30]}$. Tumor factors such as size, number, differentiation, lymphovascular invasion, and levels of $\alpha$-fetoprotein are more important risk factors for recurrence after $\mathrm{LT}^{[31,32]}$. Despite the lack of solid evidence of the role of HBV in HCC recurrence, it is still important to be aware of the carcinogenic potential of HBV, and its role in post-transplant HCC recurrence merits further studies. For non-HCC CHB patients, a positive HBsAg after LT in patients has not been shown to be associated with increased risk of de novo HCC.

\section{HBsAg negativity after liver transplantation}

Despite serum HBsAg and HBV DNA both being negative, intrahepatic HBV DNA and cccDNA can still be detected in the majority after $\mathrm{LT}^{[33,34]}$. In fact, the true HBsAg status may be masked by administration of exogenous HBIG, which is regularly topped up and never falls to an undetectable level. In addition, the level of HBsAg may be too low to be detectable by conventional qualitative assays [Figure 1]. Whether other novel biomarkers such as hepatitis B core-related antigen ( $\mathrm{HBcrAg}$ ) and HBV RNA can have a role in determining persistence of HBV infection after LT remains to be determined ${ }^{[35]}$. Even for patients receiving HBIG and NUCs with negative HBsAg and HBV DNA together with high levels of anti-HBs, HBcrAg remains detectable ${ }^{[36]}$. Altogether, the evidence suggests that the term and definition of recurrence after LT, based on conventional qualitative HBsAg testing and HBV DNA, is inadequate.

\section{CURRENT ANTIVIRAL STRATEGIES}

The current antiviral strategies are illustrated in Figure 2, with NUCs being the essential component, forming the backbone of antiviral prophylaxis. There are various permutations that can be adopted, and currently there is no standardized approach, with individual transplant centers adopting their own protocol. Although the choice of regimen has often been a topic of debate, it must be emphasized that all regimens are in fact highly effective in preventing HBV reactivation after LT. The adopted regimen used currently by each transplant center is largely determined by the cost and availability of the agents, as well as from the evolution of a previous adopted regimen built upon a combination of lamivudine (LAM) and HBIG.

\section{Hepatitis B immune globulin}

The earliest prophylaxis available was the long-term use of HBIG derived from pooled plasma of donors containing antibody to HBsAg. Protection is conferred by passive immunization with transfer of antibodies after parenteral administration. Presumably, these antibodies can neutralize circulating viral particles with the formation of immune complexes and the prevention of HBV entry into hepatocytes ${ }^{[37,38]}$. It may also promote the lysis of infected hepatocytes. 


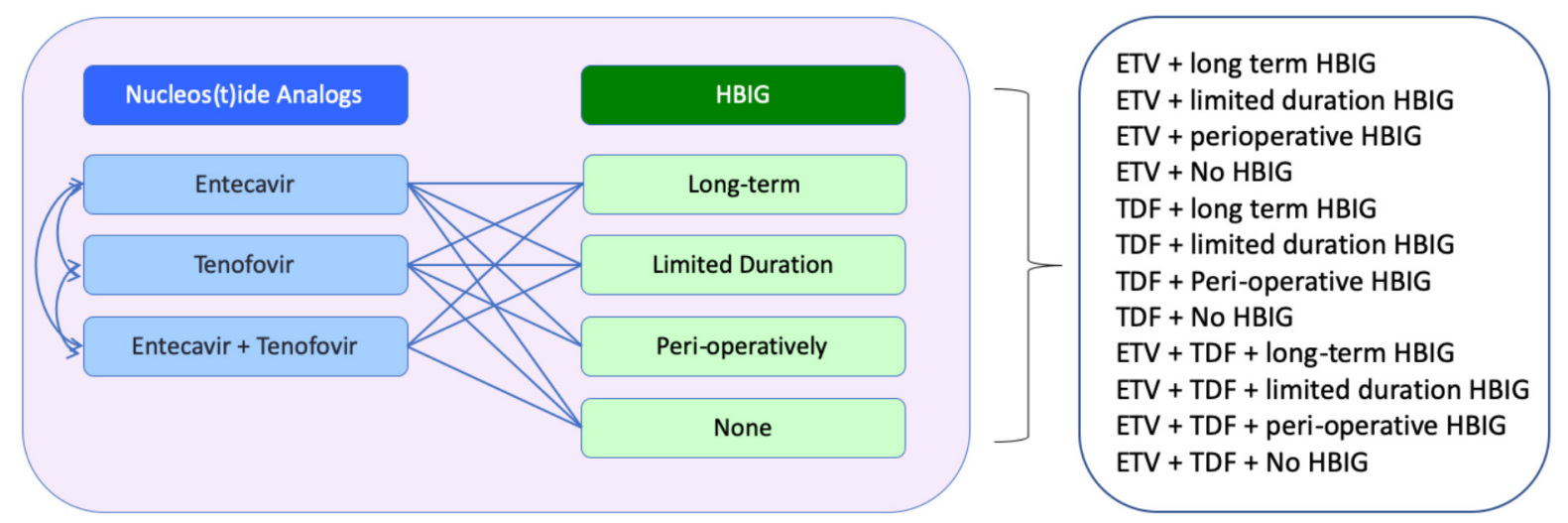

Figure 2. Currently available antiviral prophylaxis for chronic hepatitis B after liver transplantation. HBIG: Hepatitis B immunoglobulin; ETV: entecavir; TDF: tenofovir disoproxil.

The use of HBIG was a major milestone for LT in CHB and was able to significantly lower the reactivation rate by approximately $60 \%-70 \%{ }^{[39,40]}$. As HBIG is a form of passive immunoprophylaxis, short-term prophylaxis alone is ineffective as it merely delayed the occurrence of graft hepatitis ${ }^{[14]}$. Therefore, it must be administered regularly to maintain the anti-HBs above a desired arbitrary level, whereby it is deemed protective. Although very high doses were shown to lower the reactivation rate further ${ }^{[41]}$, it was still high especially for patients who were viremic or had active replication at the time of transplantation. It is likely that the HBIG would not have been able to sufficiently neutralize the circulating HBV completely and would have minimal direct antiviral activity once viral replication is established.

There are several limitations with using HBIG. Unlike NUCs, it is insufficient when used as a standalone prophylaxis. With the need for repeated parenteral injections, it is an inconvenient method of prophylaxis. HBIG is also expensive, and it was not always widely available ${ }^{[42,43]}$. With the availability of NUCs, the cost was able to be reduced significantly by the use of lower doses. Finally, the development of mutations may also inhibit the formation of immune complex. The most frequently detected mutation is found on the "a" determinant of HBsAg and provides a mechanism for immune escape ${ }^{[44]}$.

With time, a trend has emerged over the past decade towards using less and less HBIG [Figure 3]. This has only been made possible with the use of potent NUCs with high barriers to resistance ${ }^{[45]}$. As stated above, however, it is almost certain that any HBIG regimen adopted, from limited duration to perioperative or HBIG-free, is safe and effective, even for patients who are viremic at the time of transplantation. Excellent long-term outcomes have been achieved with HBIG-free regimens despite the fact that the majority of patients were viremic at the time of $\mathrm{LT}^{[20]}$. The role of HBIG has with time become less clear, especially when HBIG-free regimens have been shown to be highly effective ${ }^{[20,46]}$.

\section{Oral nucleos(t)ide analog}

The approval of LAM in 1998 revolutionized treatment of CHB patients, and it was another milestone in HBV prophylaxis after LT. The major disadvantage of LAM was the high rate of resistance, with limited treatment options available once virological relapse occurs prior to the availability of nucleotide analogs ${ }^{[47-49]}$. The combination of HBIG with LAM lowered this, and it was therefore widely adopted by transplant centers. The use of LAM also allowed for lower HBIG doses to be used, reducing the cost associated with high-dose $\mathrm{HBIG}^{[50]}$. 


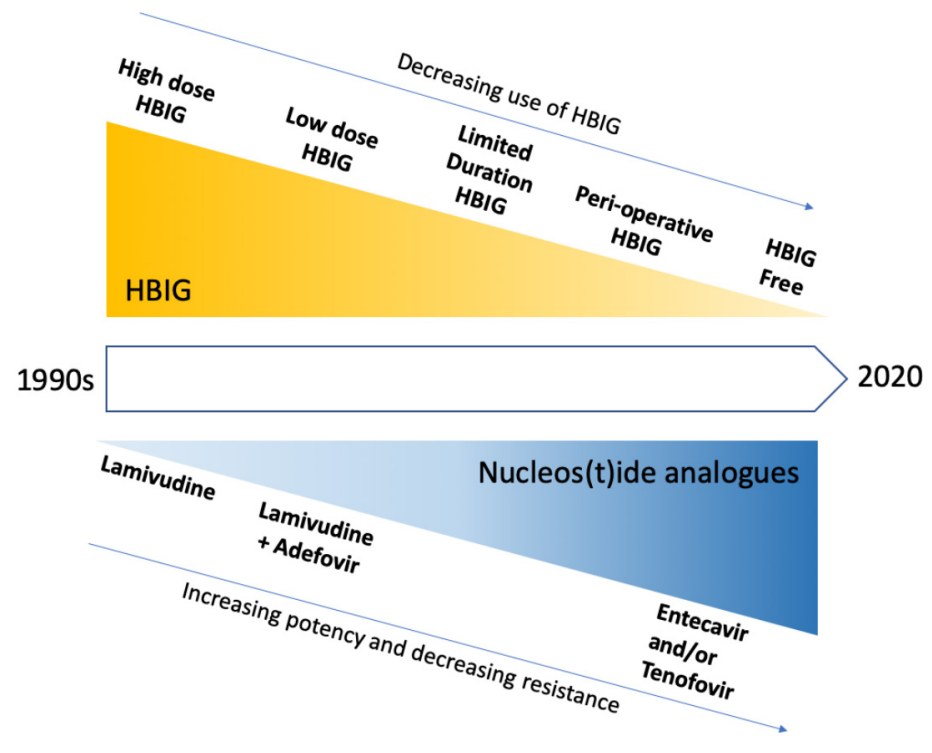

Figure 3. Shifting paradigm in antiviral prophylaxis for hepatitis B after liver transplantation. HBIG: Hepatitis B immunoglobulin.

Adefovir dipivoxil (ADV), a nucleotide analog, was approved in 2003, which was effective as rescue therapy for patients who developed LAM resistance. The availability of ADV also allowed for a combination of LAM and ADV without HBIG to be explored. For patients already on LAM and HBIG, switching HBIG to ADV was shown to be safe and effective, providing early evidence that HBIG can indeed be discontinued safely $^{[51]}$. A combination of LAM and ADV without HBIG was also shown to be effective after LT for those with LAM resistance $\mathrm{e}^{[52]}$.

Both LAM and ADV have largely been superseded by entecavir (ETV) and tenofovir (TNV), which were approved in 2005 and 2007, respectively, for CHB treatment. Due to their high barriers to resistance, both have been recommended as first line agents in HBV treatment ${ }^{[3,54]}$. This also provided the opportunity to use these agents as monoprophylaxis without HBIG for LT recipients. The early results with ETV monoprophylaxis demonstrated a high rate of HBsAg seroclearance despite the absence of HBIG, with over $90 \%$ having evidence of HBsAg seroclearance ${ }^{[19]}$. However, a proportion did have re-appearance of HBsAg with longer follow-up, raising the concern that this may impact the long-term outcome of these patients. A larger study of ETV monoprophylaxis with long-term outcome dispelled any concerns with survival at nine years of $85 \%$ and without any deaths delated to HBV reactivation ${ }^{[20]}$. It is safe to say that additional HBIG administered to these patients would not have improved their outcome and survival.

Given that TNV is also highly potent with even higher barrier to resistance, one can extrapolate from the data with ETV that TNV will likely be at least as effective ${ }^{[5,55]}$. However, TNV disoproxil (TDF) can be nephrotoxic, and it may be a less ideal agent in post-LT setting given the high rate of chronic kidney injury in post-transplant recipients together with the use of calcineurin inhibitors as primary immunosuppression ${ }^{[57]}$. The recent approval of TNV alafenamide (TAF), with a safer renal profile compared to TDF, will likely be the more suitable formulation if TNV were to be used in the post-LT setting. Early results demonstrate TAF to be both safe and effective in LT recipients ${ }^{[58-60]}$.

For patients with pre-existing resistant mutation, treatment with an agent from a different class will usually be effective. For those with resistance to nucleoside analog, treatment with nucleotide analog will be effective, and vice versa. Oral NUCs alone without HBIG has also been shown to be highly effective as 
prophylaxis after LT in patients with pre-existing resistance, with excellent long-term survival ${ }^{[61]}$.

The results to date demonstrate that current NUCs are highly efficacious in preventing HBV reactivation after LT, and this appears to be independent of the HBIG regimens. Importantly, only NUCs with high barriers to resistance should be used ${ }^{[62]}$. Older NUCs such as LAM have been associated with virological rebound secondary to the development of resistance and should not be used ${ }^{[63]}$.

\section{Therapeutic vaccination}

One of the contributing factors towards the chronicity of HBV infection is the persistent immunological dysfunction, in part due to the exhaustion of HBV-specific CD8+ and CD4+ T-cell responses with the high HBV antigen loads that occur with chronic infection ${ }^{[64]}$. Although LT drastically reduces the antigenic load with total hepatectomy and the removal of all infected hepatocytes, this alone appears to be insufficient to restore the immune deficit. Further vaccination strategies after transplantation appear to be ineffective in stimulating the production of neutralizing antibodies ${ }^{[6-68}$. Perhaps this is not unexpected given that these patients already have a life-long exposure to HBV antigens with persistent failure to mount an effective immune response.

\section{DURATION OF PROPHYLAXIS}

Life-long prophylaxis is usually required irrespective of the regimen used. This is based on the rationale that $\mathrm{HBV}$ is not completely eradicated at the time of LT. As NUCs are the essential component, it is continued long term. For centers using additional HBIG, whether HBIG is used long term will be dependent on the adopted approach of each center, although they are increasingly moving away from giving long-term HBIG. A few studies have demonstrated that stopping all prophylaxis is possible, but likely only for a minority ${ }^{[69]}$. For those with undetectable HBV DNA at the time of LT, and with no evidence of intrahepatic total and cccDNA, weaning of prophylaxis was shown to be feasible. However, this is likely only possible in a highly selected group of patients with very low risk of reactivation ${ }^{[70]}$. Occult HBV likely persists in most patients after LT, and intrahepatic HBV DNA can be detected in most patients after LT despite being negative for both HBsAg and HBV DNA in the serum ${ }^{[33]}$.

\section{ANTI-HBC POSITIVE GRAFTS}

The development of anti-HBc is an indicator of previous exposure or infection to HBV, and intrahepatic cccDNA can still be detected in grafts from anti-HBc positive donors after LT. However, the use of anti$\mathrm{HBc}$ positive graft as extended criteria donors is acceptable for many centers, especially in regions where HBV remains endemic, and donor organs remain scarce ${ }^{[1,72]}$. As occult HBV infection can reside in these grafts, there is a risk of reactivation after LT, and life-long prophylaxis is required ${ }^{[73]}$. With appropriate prophylaxis, good long-term outcomes can be achieved ${ }^{[74]}$. For CHB recipients who already require prophylaxis, there is no additional therapy. As the occult HBV infection is already inside the graft, HBIG is unlikely to be of benefit. Although LAM has been widely used in these instances, HBsAg seropositivity and/or detectable HBV DNA can occur, therefore it would be prudent to use a newer agent with less resistance risk ${ }^{[75]}$.

\section{HBSAG+ GRAFTS}

In areas where $\mathrm{HBV}$ infection remains endemic, $2 \%-15 \%$ of consented grafts may be positive for HBsAg and may serve as an important source for recipients already with CHB infection. Although the use of HBsAg+ grafts has been associated with good outcomes, specialized protocols are required for stringent assessment of graft quality to exclude underlying fibrosis/cirrhosis and $\mathrm{HCC}^{[76,77]}$. The use of HBIG in this setting is unlikely to be of any clinical benefit as the graft is already chronically infected, and life-long NUCs will be 
required, together with regular surveillance for HCC development.

\section{HEPATITIS D VIRUS CO-INFECTION}

For patients co-infected with hepatitis D virus (HDV), the default prophylaxis is a combination of NUCs + HBIG, with excellent outcomes. HDV is a defective virus and is dependent on HBsAg coating for viral propagation. Therefore, it would seem that HBIG would be essential, given the minimal effect of NUCs on HBsAg. However, several studies have shown that discontinuation of HBIG is safe and associated with excellent outcome, even with HBsAg reappearance ${ }^{[78-81]}$. Perhaps this is not surprising given that, quantitatively, the HBsAg remains at extremely low levels (often just above the level of detectability) and likely insufficient for effective HDV reactivation. However, long-term NUCs will be required, as HBV reactivation will lead to HDV reactivation ${ }^{[82]}$.

\section{FUTURE DIRECTIONS}

Despite current NUCs being highly effective in suppressing HBV replication and preventing graft hepatitis and subsequent graft loss, it is unable to eradicate HBV completely ${ }^{[83]}$. The reason for this is because NUCs only act on the downstream components of the viral replication cycle, where upstream activity continues unabated with continual transcription and translation of viral proteins from very stable cccDNA templates ${ }^{[84]}$. Novel agents targeting different parts of the HBV cycle are currently under clinical trials. These include inhibition of viral entry via the NTCP receptor, interference of mRNA to inhibit viral protein synthesis, inhibition of capsid formation, and release of virions. Inhibition of viral entry is of special interest as it may potentially prevent infection of an HBV-naïve graft. Interestingly, cyclosporin, a calcineurin inhibitor that is also used as an immunosuppressive drug in solid organ transplantation, has also been shown to inhibit HBV entry ${ }^{[85]}$.

As LT prophylaxis is already highly efficacious in viral suppression, any new therapy must further improve the clinical outcome significantly, and this will likely be the establishment of a functional cure, whereby long-term prophylaxis is no longer required. In fact, by removing all the infected hepatocytes at the time of LT, and with the high rate of HBsAg seroclearance observed, it appears that functional cure is achieved. However, this is not a true functional cure, as there is no immune control, and reactivation will occur in the absence of prophylaxis. However, it does present a major opportunity for functional cure, as the prerequisite conditions of cccDNA and intrahepatic HBV elimination have been satisfied. The only step remaining would be the restoration of immune control. In addition to vaccination, other immunotherapeutic strategies to stimulate the innate response and block inhibitory pathways are currently being explored. These include toll-like receptor (TLR agonists) and anti-PD1/anti-PDL-1, respectively ${ }^{[86,87]}$. However, this remains a challenge with the use of long-term immunosuppression, and the results with therapeutic vaccines have not been encouraging. Although other immunotherapeutic strategies may be more effective, the risk of precipitating graft rejection or de novo autoimmune hepatitis remains a risk ${ }^{[88]}$.

\section{SUMMARY}

Currently available antiviral prophylaxis using NUCs \pm HBIG is highly effective in preventing HBV reactivation after LT. Only NUCs with high potency and high barriers to resistance should be used. Over the past decade, there has been a trend towards using less HBIG, with HBIG-free regimens showing excellent long-term outcomes and survival. The definition of HBV recurrence after LT remains inadequate, resulting in inconsistencies when used as marker for clinical efficacy. More sensitive biomarkers of viral persistence and reactivation will contribute to better understanding of HBV kinetics after LT and lead to a standardized approach in preventing reactivation. Although cessation of prophylaxis may be feasible in a highly selected group, life-long prophylaxis is recommended outside of clinical trial settings. Future novel 
agents may restore the immune control of HBV, whereby antiviral therapy can be safely discontinued.

\section{DECLARATIONS}

\section{Authors' contributions}

The author contributed solely to the article.

\section{Availability of data and materials}

Not applicable.

\section{Financial support and sponsorship}

None.

\section{Conflicts of interest}

The author declared that there are no conflicts of interest.

\section{Ethical approval and consent to participate}

Not applicable.

\section{Consent for publication}

Not applicable.

\section{Copyright}

(c) The Author(s) 2021.

\section{REFERENCES}

1. Schweitzer A, Horn J, Mikolajczyk RT, Krause G, Ott JJ. Estimations of worldwide prevalence of chronic hepatitis B virus infection: a systematic review of data published between 1965 and 2013. Lancet 2015;386:1546-55. DOI PubMed

2. Fung J, Lai CL, Yuen MF. Management of chronic hepatitis B in severe liver disease. World J Gastroenterol 2014;20:16053-61. DOI PubMed PMC

3. Shim JH, Lee HC, Kim KM, et al. Efficacy of entecavir in treatment-naive patients with hepatitis B virus-related decompensated cirrhosis. J Hepatol 2010;52:176-82. DOI PubMed

4. Hosaka T, Suzuki F, Kobayashi M, et al. Long-term entecavir treatment reduces hepatocellular carcinoma incidence in patients with hepatitis B virus infection. Hepatology 2013;58:98-107. DOI PubMed

5. Fung J, Mak LY, Chan A, et al. Trends in Liver Transplantation for Chronic Hepatitis B in an Era of Highly Potent Antiviral Therapies. Liver Transpl 2021;27:134-9. DOI PubMed

6. Fung J. Management of chronic hepatitis B before and after liver transplantation. World J Hepatol 2015;7:1421-6. DOI PubMed PMC

7. Ciesek S, Helfritz FA, Lehmann U, et al. Persistence of occult hepatitis B after removal of the hepatitis B virus-infected liver. J Infect Dis 2008;197:355-60. DOI PubMed

8. Jin Y, Gao H, Chen H, et al. Identification and impact of hepatitis B virus DNA and antigens in pancreatic cancer tissues and adjacent non-cancerous tissues. Cancer Lett 2013;335:447-54. DOI PubMed

9. Lai KN, Ho RT, Tam JS, Lai FM. Detection of hepatitis B virus DNA and RNA in kidneys of HBV related glomerulonephritis. Kidney Int 1996;50:1965-77. DOI PubMed

10. Lu L, Zhang HY, Yueng YH, et al. Intracellular levels of hepatitis B virus DNA and pregenomic RNA in peripheral blood mononuclear cells of chronically infected patients. J Viral Hepat 2009;16:104-12. DOI PubMed

11. Stoll-Becker S, Repp R, Glebe D, et al. Transcription of hepatitis B virus in peripheral blood mononuclear cells from persistently infected patients. J Virol 1997;71:5399-407. DOI PubMed PMC

12. Gao S, Duan ZP, Chen Y, et al. Compartmental HBV evolution and replication in liver and extrahepatic sites after nucleos/tide analogue therapy in chronic hepatitis B carriers. J Clin Virol 2017;94:8-14. DOI PubMed

13. Lau KCK, Osiowy C, Giles E, et al. Deep sequencing shows low-level oncogenic hepatitis B virus variants persists post-liver transplant despite potent anti-HBV prophylaxis. J Viral Hepat 2018;25:724-732. DOI PubMed

14. Todo S, Demetris AJ, Van Thiel D, Teperman L, Fung JJ, Starzl TE. Orthotopic liver transplantation for patients with hepatitis B virus-related liver disease. Hepatology 1991;13:619-26. PubMed PMC

15. Loomba R, Rowley AK, Wesley R, et al. Hepatitis B immunoglobulin and Lamivudine improve hepatitis B-related outcomes after liver transplantation: meta-analysis. Clin Gastroenterol Hepatol 2008;6:696-700. DOI PubMed PMC 
16. Katz LH, Paul M, Guy DG, Tur-Kaspa R. Prevention of recurrent hepatitis B virus infection after liver transplantation: hepatitis B immunoglobulin, antiviral drugs, or both? Transpl Infect Dis 2010;12:292-308. DOI PubMed

17. Wang P, Tam N, Wang H, et al. Is hepatitis B immunoglobulin necessary in prophylaxis of hepatitis B recurrence after liver transplantation? PLoS One 2014;9:e104480. DOI PubMed PMC

18. Mak LY, Wong DK, Pollicino T, Raimondo G, Hollinger FB, Yuen MF. Occult hepatitis B infection and hepatocellular carcinoma: Epidemiology, virology, hepatocarcinogenesis and clinical significance. J Hepatol 2020;73:952-64. DOI PubMed

19. Fung J, Cheung C, Chan SC, et al. Entecavir monotherapy is effective in suppressing hepatitis B virus after liver transplantation. Gastroenterology 2011;141:1212-9. DOI PubMed

20. Fung J, Wong T, Chok K, et al. Long-term outcomes of entecavir monotherapy for chronic hepatitis B after liver transplantation: Results up to 8 years. Hepatology 2017;66:1036-44. DOI PubMed

21. Lo CM, Fung JT, Lau GK, et al. Development of antibody to hepatitis B surface antigen after liver transplantation for chronic hepatitis B. Hepatology 2003;37:36-43. DOI PubMed

22. Fung J, Lo R, Chan SC, et al. Outcomes including liver histology after liver transplantation for chronic hepatitis B using oral antiviral therapy alone. Liver Transpl 2015;21:1504-10. DOI PubMed

23. Han SH, Reddy KR, Keeffe EB, et al; NIH HBV OLT Study Group. Clinical outcomes of liver transplantation for HBV-related hepatocellular carcinoma: data from the NIH HBV OLT study. Clin Transplant 2011;25:E152-62. DOI PubMed PMC

24. Hshieh TT, Sundaram V, Najarian RM, Hanto DW, Karp SJ, Curry MP. Hepatitis B surface antigen as a marker for recurrent, metastatic hepatocellular carcinoma after liver transplantation. Liver Transpl 2012;18:995-8. DOI PubMed

25. Faria LC, Gigou M, Roque-Afonso AM, et al. Hepatocellular carcinoma is associated with an increased risk of hepatitis B virus recurrence after liver transplantation. Gastroenterology 2008;134:1890-9; quiz 2155. DOI PubMed

26. Fung J, Wong DK, Tanaka Y, et al. Quantitative hepatitis B surface antigen in predicting recurrence of hepatitis B-related hepatocellular carcinoma after liver transplantation. Hepatoma Res 2018;4:62. DOI

27. Qasim W, Brunetto M, Gehring AJ, et al. Immunotherapy of HCC metastases with autologous T cell receptor redirected T cells, targeting HBsAg in a liver transplant patient. J Hepatol 2015;62:486-91. DOI PubMed

28. Campsen J, Zimmerman M, Trotter J, et al. Liver transplantation for hepatitis B liver disease and concomitant hepatocellular carcinoma in the United States With hepatitis B immunoglobulin and nucleoside/nucleotide analogues. Liver Transpl 2013;19:1020-9. DOI PubMed

29. Kornberg A, Kupper B, Tannapfel A, et al. Long-term survival after recurrent hepatocellular carcinoma in liver transplant patients: clinical patterns and outcome variables. Eur J Surg Oncol 2010;36:275-80. DOI PubMed

30. Dugum M, Hanouneh I, Lopez R, Aucejo F, Eghtesad B, Zein N. Hepatocellular Carcinoma in the Setting of Chronic Hepatitis B Virus Infection: Tumor Recurrence and Survival Rates After Liver Transplantation. Transplant Proc 2015;47:1939-44. DOI PubMed

31. Mazzola A, Costantino A, Petta S, et al. Recurrence of hepatocellular carcinoma after liver transplantation: an update. Future Oncol 2015;11:2923-36. DOI PubMed

32. Fahrner R, Dondorf F, Ardelt M, Dittmar Y, Settmacher U, Rauchfuß F. Liver transplantation for hepatocellular carcinoma - factors influencing outcome and disease-free survival. World J Gastroenterol 2015;21:12071-82. DOI PubMed PMC

33. Hussain M, Soldevila-Pico C, Emre S, Luketic V, Lok AS; NIH HBV-OLT Study Group. Presence of intrahepatic (total and ccc) HBV DNA is not predictive of HBV recurrence after liver transplantation. Liver Transpl 2007;13:1137-44. DOI PubMed

34. Yasunaka T, Takaki A, Yagi T, et al. Serum hepatitis B virus DNA before liver transplantation correlates with HBV reinfection rate even under successful low-dose hepatitis B immunoglobulin prophylaxis. Hepatol Int 2011;5:918-26. DOI PubMed PMC

35. Mak LY, Wong DK, Cheung KS, Seto WK, Lai CL, Yuen MF. Review article: hepatitis B core-related antigen (HBcrAg): an emerging marker for chronic hepatitis B virus infection. Aliment Pharmacol Ther 2018;47:43-54. DOI PubMed

36. Matsuzaki T, Tatsuki I, Otani M, et al. Significance of hepatitis B virus core-related antigen and covalently closed circular DNA levels as markers of hepatitis B virus re-infection after liver transplantation. J Gastroenterol Hepatol 2013;28:1217-22. DOI PubMed

37. Shouval D, Samuel D. Hepatitis B immune globulin to prevent hepatitis B virus graft reinfection following liver transplantation: a concise review. Hepatology 2000;32:1189-95. DOI PubMed

38. Celis E, Abraham KG, Miller RW. Modulation of the immunological response to hepatitis B virus by antibodies. Hepatology 1987;7:563-8. DOI PubMed

39. Samuel D, Bismuth A, Mathieu D, et al. Passive immunoprophylaxis after liver transplantation in HBsAg-positive patients. Lancet 1991;337:813-5. DOI PubMed

40. Samuel D, Muller R, Alexander G, et al. Liver transplantation in European patients with the hepatitis B surface antigen. $N$ Engl J Med 1993;329:1842-7. DOI PubMed

41. Terrault NA, Zhou S, Combs C, et al. Prophylaxis in liver transplant recipients using a fixed dosing schedule of hepatitis B immunoglobulin. Hepatology 1996;24:1327-33. DOI PubMed

42. Chan AC, Fung JY, Lo CM. Liver transplantation and hepatitis B virus infection: towards an immunoglobulin-free antiviral treatment after transplantation. Curr Opin Organ Transplant 2016;21:219-23. DOI PubMed

43. Stravitz RT, Shiffman ML, Kimmel M, et al. Substitution of tenofovir/emtricitabine for Hepatitis B immune globulin prevents recurrence of Hepatitis B after liver transplantation. Liver Int 2012;32:1138-45. DOI PubMed

44. McMahon G, Ehrlich PH, Moustafa ZA, et al. Genetic alterations in the gene encoding the major HBsAg: DNA and immunological analysis of recurrent HBsAg derived from monoclonal antibody-treated liver transplant patients. Hepatology 1992;15:757-66. DOI PubMed

45. Nasir M, Wu GY. Prevention of HBV Recurrence after Liver Transplant: A Review. J Clin Transl Hepatol 2020;8:150-60. DOI 
PubMed PMC

46. Muthiah MD, Tan EY, Chua SHM, et al. Nucleoside analog monotherapy for prophylaxis in Hepatitis B liver transplant patients is safe and efficacious. Hepatol Int 2020;14:57-69. DOI PubMed

47. Mutimer D, Dusheiko G, Barrett C, et al. Lamivudine without HBIg for prevention of graft reinfection by hepatitis B: long-term follow-up. Transplantation 2000;70:809-15. DOI PubMed

48. Lo CM, Cheung ST, Lai CL, et al. Liver transplantation in Asian patients with chronic hepatitis B using lamivudine prophylaxis. Ann Surg 2001;233:276-81. DOI PubMed PMC

49. Perrillo RP, Wright T, Rakela J, et al; Lamivudine North American Transplant Group. A multicenter United States-Canadian trial to assess lamivudine monotherapy before and after liver transplantation for chronic hepatitis B. Hepatology 2001;33:424-32. DOI PubMed

50. Angus PW, McCaughan GW, Gane EJ, Crawford DH, Harley H. Combination low-dose hepatitis B immune globulin and lamivudine therapy provides effective prophylaxis against posttransplantation hepatitis B. Liver Transpl 2000;6:429-33. DOI PubMed

51. Angus PW, Patterson SJ, Strasser SI, McCaughan GW, Gane E. A randomized study of adefovir dipivoxil in place of HBIG in combination with lamivudine as post-liver transplantation hepatitis B prophylaxis. Hepatology 2008;48:1460-6. DOI PubMed

52. Lo CM, Liu CL, Lau GK, Chan SC, Ng IO, Fan ST. Liver transplantation for chronic hepatitis B with lamivudine-resistant YMDD mutant using add-on adefovir dipivoxil plus lamivudine. Liver Transpl 2005;11:807-13. DOI PubMed

53. Terrault NA, Bzowej NH, Chang KM, Hwang JP, Jonas MM, Murad MH; American Association for the Study of Liver Diseases. AASLD guidelines for treatment of chronic hepatitis B. Hepatology 2016;63:261-83. DOI PubMed PMC

54. Association for the Study of the Liver. EASL 2017 Clinical Practice Guidelines on the management of hepatitis B virus infection. $J$ Hepatol 2017;67:370-98. DOI PubMed

55. Vasudevan A, Ardalan ZS, Ahmed N, et al. Long-term safety and efficacy of tenofovir disoproxil fumarate substitution for hepatitis B immunoglobulin following liver transplantation. JGH Open 2018;2:288-94. DOI PubMed PMC

56. Manini MA, Whitehouse G, Bruce M, et al. Entecavir or tenofovir monotherapy prevents HBV recurrence in liver transplant recipients: A 5-year follow-up study after hepatitis B immunoglobulin withdrawal. Dig Liver Dis 2018;50:944-53. DOI PubMed

57. Ojo AO, Held PJ, Port FK, et al. Chronic renal failure after transplantation of a nonrenal organ. N Engl J Med 2003;349:931-40. DOI PubMed

58. Sripongpun P, Mannalithara A, Kwo PY, Kim WR. Potential benefits of switching liver transplant recipients to Tenofovir Alafenamide Prophylaxis. Clin Gastroenterol Hepatol 2020;18:747-9. DOI PubMed

59. Rashidi-Alavijeh J, Straub K, Achterfeld A, Wedemeyer H, Willuweit K, Herzer K. Safety and efficacy of tenofovir alafenamide in liver transplant recipients: a single center experience. Transpl Infect Dis ;2020:e13522. DOI PubMed

60. Saab S, Song D, Challita YP, et al. Long-term outcomes with oral therapy in liver transplant recipients with hepatitis B. Clin Transplant 2019;33:e13740. DOI PubMed

61. Fung J, Wong T, Chok K, et al. Oral nucleos(t)ide analogs alone after liver transplantation in chronic hepatitis B with preexisting rt204 mutation. Transplantation 2017;101:2391-8. DOI PubMed

62. Zheng JN, Zou TT, Zou H, et al. Comparative efficacy of oral nucleotide analogues for the prophylaxis of hepatitis B virus recurrence after liver transplantation: a network meta-analysis. Expert Rev Anti Infect Ther 2016;14:979-87. DOI PubMed

63. Fung J, Chan SC, Cheung C, et al. Oral nucleoside/nucleotide analogs without hepatitis B immune globulin after liver transplantation for hepatitis B. Am J Gastroenterol 2013;108:942-8. DOI PubMed

64. Wherry EJ. T cell exhaustion. Nat Immunol 2011;12:492-9. DOI PubMed

65. Angelico M, Di Paolo D, Trinito MO, et al. Failure of a reinforced triple course of hepatitis B vaccination in patients transplanted for HBV-related cirrhosis. Hepatology 2002;35:176-81. DOI PubMed

66. Lo CM, Liu CL, Chan SC, Lau GK, Fan ST. Failure of hepatitis B vaccination in patients receiving lamivudine prophylaxis after liver transplantation for chronic hepatitis B. J Hepato;43:283-7. DOI PubMed

67. Rosenau J, Hooman N, Rifai K, et al. Hepatitis B virus immunization with an adjuvant containing vaccine after liver transplantation for hepatitis B-related disease: failure of humoral and cellular immune response. Transpl Int 2006;19:828-33. DOI PubMed

68. Wong TCL, Fung JYY, Chok KSH, et al. Hepatitis B vaccination in patients receiving oral antiviral therapy without hepatitis B immunoglobulin after liver transplant. Transplant Proc 2018;50:3681-8. DOI PubMed

69. Lenci I, Tisone G, Di Paolo D, et al. Safety of complete and sustained prophylaxis withdrawal in patients liver-transplanted for HBVrelated cirrhosis at low risk of HBV recurrence. J Hepatol 2011;55:587-93. DOI PubMed

70. Lenci I, Baiocchi L, Tariciotti L, et al. Complete hepatitis B virus prophylaxis withdrawal in hepatitis B surface antigen-positive liver transplant recipients after longterm minimal immunosuppression. Liver Transpl 2016;22:1205-13. DOI PubMed

71. Vodkin I, Kuo A. Extended criteria donors in liver transplantation. Clin Liver Dis 2017;21:289-301. DOI PubMed

72. Cholongitas E, Papatheodoridis GV, Burroughs AK. Liver grafts from anti-hepatitis B core positive donors: a systematic review. $J$ Hepatol 2010;52:272-9. DOI PubMed

73. Perrillo R. Hepatitis B virus prevention strategies for antibody to hepatitis B core antigen-positive liver donation: a survey of North American, European, and Asian-Pacific transplant programs. Liver Transpl 2009;15:223-32. DOI PubMed

74. Lo CM, Fan ST, Liu CL, et al. Safety and outcome of hepatitis B core antibody-positive donors in right-lobe living donor liver transplantation. Liver Transpl 2003;9:827-32. DOI PubMed

75. Wong TC, Fung JY, Cui TY, et al. Liver transplantation using hepatitis B core positive grafts with antiviral monotherapy prophylaxis. J Hepatol 2019;70:1114-22. DOI PubMed

76. Ballarin R, Cucchetti A, Russo FP, et al. Long term follow-up and outcome of liver transplantation from hepatitis B surface antigen 
positive donors. World J Gastroenterol 2017;23:2095-105. DOI PubMed PMC

77. Loggi E, Micco L, Ercolani G, et al. Liver transplantation from hepatitis B surface antigen positive donors: a safe way to expand the donor pool. J Hepatol 2012;56:579-85. DOI PubMed

78. Caccamo L. Long-term nucleos(t)ide analog(s) monoprophylaxis in Delta coinfected liver transplant recipients. Transpl Infect Dis 2017:19. DOI PubMed

79. Cholongitas E, Goulis I, Antoniadis N, et al. Nucleos(t)ide analog(s) prophylaxis after hepatitis B immunoglobulin withdrawal against hepatitis B and D recurrence after liver transplantation. Transpl Infect ;18:667-73. DOI PubMed

80. Ocal S, Korkmaz M, Harmanci O, et al. Hepatitis B- and hepatitis D-virus-related liver transplant: single-center data. Exp Clin Transplant 2015;13 Suppl 1:133-8. PubMed

81. Fernandez I, Loinaz C, Hernandez O, et al. Tenofovir/entecavir monotherapy after hepatitis B immunoglobulin withdrawal is safe and effective in the prevention of hepatitis B in liver transplant recipients. Transpl Infect Dis 2015;17:695-701. DOI PubMed

82. Miyaaki H, Tamada Y, Hayashi K, et al. Recurrent hepatitis B and D virus infection in a liver transplant recipient. Transplant Proc 2017;49:175-7. DOI PubMed

83. Mak LY, Seto WK, Fung J, Yuen MF. Novel developments of hepatitis B: treatment goals, agents and monitoring tools. Expert Rev Clin Pharmacol 2019;12:109-20. DOI PubMed

84. Fung J, Lai CL, Seto WK, Yuen MF. Emerging drugs for the treatment of hepatitis B. Expert Opin Emerg Drugs 2016;21:183-93. DOI PubMed

85. Shimura S, Watashi K, Fukano K, et al. Cyclosporin derivatives inhibit hepatitis B virus entry without interfering with NTCP transporter activity. J Hepatol 2017;66:685-92. DOI PubMed PMC

86. Gane E, Verdon DJ, Brooks AE, et al. Anti-PD-1 blockade with nivolumab with and without therapeutic vaccination for virally suppressed chronic hepatitis B: A pilot study. J Hepatol 2019;71:900-7. DOI PubMed

87. Ma Z, Cao Q, Xiong Y, Zhang E, Lu M. Interaction between hepatitis B virus and Toll-like receptors: Current status and potential therapeutic use for chronic hepatitis B. Vaccines (Basel) 2018;6:6. DOI PubMed PMC

88. Hu B, Yang XB, Sang XT. Liver graft rejection following immune checkpoint inhibitors treatment: a review. Med Oncol 2019;36:94. DOI PubMed 